Published in final edited form as:

Virus Res. 2011 September ; 160(1-2): 351-359. doi:10.1016/j.virusres.2011.07.012.

\title{
Limited Effects of Muc1 Deficiency on Mouse Adenovirus Type 1 Respiratory Infection
}

\author{
Y Nguyen ${ }^{a}, \dagger$, Megan C. Procario ${ }^{a}$, Shanna L. Ashley ${ }^{b}$, Wanda K. O'Neal' ${ }^{c}$, Raymond J. \\ Pickles $^{c, d}$, and Jason B. Weinberg ${ }^{a, b}$ \\ aDepartment of Pediatrics and Communicable Diseases, University of Michigan, Ann Arbor, \\ Michigan (Y.Nguyen@UTSouthwestern.edu, mcprocar@umich.edu, jbwein@umich.edu) \\ ${ }^{b}$ Department of Microbiology and Immunology, University of Michigan, Ann Arbor, Michigan \\ (ashleyxy@umich.edu)
}

${ }^{\circ}$ Cystic Fibrosis/Pulmonary Research and Treatment Center, University of North Carolina at Chapel Hill, Chapel Hill, North Carolina (woneal@med.unc.edu, raymond_pickles@med.unc.edu)

dDepartment of Microbiology and Immunology, University of North Carolina at Chapel Hill, Chapel Hill, North Carolina

\begin{abstract}
Muc1 (MUC1 in humans) is a membrane-tethered mucin that exerts anti-inflammatory effects in the lung during bacterial infection. Muc1 and other mucins are also likely to form a protective barrier in the lung. We used mouse adenovirus type 1 (MAV-1, also known as MAdV-1) to determine the role of Muc1 in the pathogenesis of an adenovirus in its natural host. Following intranasal inoculation of wild type mice, we detected increased TNF- $\alpha$, a cytokine linked to Muc1 production, but no consistent changes in the production of lung Muc1, Muc5ac or overall lung mucus production. Viral loads were modestly higher in the lungs of $\mathrm{Muc}^{-/-}$mice compared to Muc ${ }^{+/+}$mice at several early time points but decreased to similar levels by 14 days post infection in both groups. However, cellular inflammation and the expression of CXCL1, CCL5, and CCL2 did not significantly differ between $\mathrm{Muc}^{-/-}$and $\mathrm{Muc}^{+/+}$mice. Our data therefore suggest that Muc1 may contribute to a physical barrier that protects against MAV-1 respiratory infection. However, our data do not reveal an anti-inflammatory effect of Muc1 that contributes to MAV-1 pathogenesis..
\end{abstract}

\section{Keywords}

mucin; Muc1; adenovirus

(C) 2011 Elsevier B.V. All rights reserved

Corresponding Author: Jason B. Weinberg, M.D., Pediatric Infectious Diseases, 7510A MSRB I, 1150 West Medical Center Drive, Ann Arbor, Michigan 48109-6584. Phone: (734) 764-6264. Fax: (734) 936-7083. jbwein@umich.edu.

${ }^{\dagger}$ Current affiliation: Graduate School of Biomedical Sciences, University of Texas Southwestern, Dallas, Texas

Publisher's Disclaimer: This is a PDF file of an unedited manuscript that has been accepted for publication. As a service to our customers we are providing this early version of the manuscript. The manuscript will undergo copyediting, typesetting, and review of the resulting proof before it is published in its final citable form. Please note that during the production process errors may be discovered which could affect the content, and all legal disclaimers that apply to the journal pertain. 


\section{Introduction}

Many epithelial surfaces are covered by a layer of mucus that serves as a barrier between the external environment and the host. The mucins are glycosylated proteins that are major constituents of these mucus layers. The gel-forming mucins are secreted proteins that are produced by the surface epithelium and submucosal glands and are released both constitutively and in response to a variety of stimuli (Thornton et al., 2008). The membranetethered (cell-surface) mucins are physically associated with epithelial cells via membranespanning domains (Hattrup and Gendler, 2008). In the airways, mucus contributes to host defense by trapping pathogens and other particles and facilitating their clearance from the lungs by ciliary transport and cough (Knowles and Boucher, 2002). In some cases, mucins may have functions beyond serving as a protective barrier. For instance, MUC1 (Muc1 in nonhumans) is a membrane-tethered mucin that is expressed on a variety of cell types including most secretory epithelial cells as well as some hematopoietic cells (Chang et al., 2000; Gendler, 2001). In addition to serving as a cell-surface adhesion site for Pseudomonas aeruginosa (Lillehoj et al., 2001), Muc1 has an anti-inflammatory role. Muc1 negatively regulates signaling through a variety of Toll-like receptors (TLRs) in vitro (Ueno et al., 2008), and knockdown of MUC1 in a lung epithelial cell line results in increased tumor necrosis factor (TNF)- $\alpha$ production following respiratory syncytial virus (RSV) infection (Li et al., 2010). In vivo, there is increased inflammation and enhanced pulmonary clearance of P. aeruginosa from lungs of $\mathrm{Muc}^{-/-}$mice (Lu et al., 2006).

Increased mucus production is a common feature of respiratory viral infections and is thought to contribute to the symptoms of acute infection and to virus-induced asthma exacerbations (Footitt and Johnston, 2009). Many viruses induce lung mucus production in animal models, including respiratory syncytial virus (RSV) (Moore et al., 2009), human metapneumovirus (Hamelin et al., 2006), and human rhinovirus (Bartlett et al., 2008). TNF$\alpha$ induced by RSV infection upregulates MUC1 production in a human lung epithelial cell line (Li et al., 2010), but to our knowledge no other reports exist that describe the effects of viral infection on MUC1/Muc1 production in vitro or in vivo.

Human adenoviruses (HAdVs) are common causes of respiratory infections that can present with syndromes ranging from mild upper respiratory tract infections to more severe, lifethreatening manifestations (Horwitz, 2001). Immunocompromised patients are at risk for greatly increased morbidity and mortality from HAdV infections (Kojaoghlanian et al., 2003; Walls et al., 2003). Little is known about the role of mucus in HAdV pathogenesis. An empty HAdV-based vector does not induce mucus production in mouse lungs (Therien et al., 2008). HAdV-mediated gene transfer in mice engineered to express the human coxsackievirus and adenovirus receptor (CAR) is more efficient in the lungs of Muc1deficient mice (Stonebraker et al., 2004), suggesting that Muc1 may serve as a barrier to adenovirus infection. Exposure of mice to HAdV does not result in a fully permissive infection (Ginsberg et al., 1991; Kajon et al., 2003). This species-specificity of the adenoviruses has precluded a thorough analysis of interactions between lung mucins and an adenovirus in the natural host of the virus.

We have established mouse adenovirus type 1 (MAV-1, also known as MAdV-1) as a useful model to study the pathogenesis of adenovirus respiratory infection (Anderson et al., 2009; Weinberg et al., 2007; Weinberg et al., 2005). In this report, we use MAV-1 to characterize the role of Muc1 in the pathogenesis of adenovirus respiratory infection, taking advantage of the ability to study the pathogenesis of an adenovirus in its natural host. We demonstrate that acute MAV-1 respiratory infection does not substantially increase Muc1 expression in the lungs of mice. MAV-1 viral loads were higher in the lungs of Muc1-deficient mice, but Muc1 deficiency had minimal effect on MAV-1-induced pulmonary inflammation. Our data 
suggest that Muc1 may serve as a physical barrier to MAV-1 infection in the lungs. However, the previously identified negative regulatory effect of Muc1 on inflammatory signaling pathways does not appear to make substantial contributions to MAV-1 pathogenesis.

\section{Materials and Methods}

\subsection{Virus}

MAV-1 was grown in NIH 3 T6 fibroblasts and titers were determined by plaque assay as previously described (Cauthen et al., 2007).

\subsection{Mice}

Mice with targeted deletions of the Muc1 gene ( $\mathrm{Muc1}^{-1-}$ mice) backcrossed onto a C57BL/ 6 background (Spicer et al., 1995) were obtained from Sandra Gendler (Mayo Clinic, Scottsdale, AZ) and bred at the University of Michigan. Genotype was confirmed for all Muc1 $^{-/-}$animals (data not shown). Wild type C57BL/6 mice (referred to hereafter as $\mathrm{Muc}^{+/+}$mice) used as controls were obtained from The Jackson Laboratory (Bar Harbor, ME). All animal work was conducted according to relevant national and international guidelines. All animal work was approved by the University of Michigan Committee on the Use and Care of Animals (approval \#9054).

\subsection{Mouse Infections}

Mice were anesthetized and inoculated intranasally (i.n.) with $10^{5}$ p.f.u. of MAV-1 diluted to a total volume of $40 \mu \mathrm{l}$ with sterile phosphate-buffered saline (PBS). In some experiments, mock infected control animals were instead inoculated i.n. with an equivalent volume of conditioned media diluted to a total volume of $40 \mu \mathrm{l}$ with PBS. Before infection and then again at multiple time points post infection, organs were harvested and snap-frozen on dry ice and stored at $-80^{\circ} \mathrm{C}$.

\subsection{DNA and RNA Isolation from Mouse Organs}

DNA was extracted from the middle lobe of the right lung or approximately $30 \mathrm{mg}$ of the spleen using the DNeasy Tissue Kit (Qiagen, Valencia, CA). Total RNA was extracted from lungs as previously described (Nguyen et al., 2008). In brief, approximately one-third of each lung was homogenized using sterile glass beads in a mini Beadbeater (Biospec Products, Bartlesville, OK) for 30 seconds in $1 \mathrm{ml}$ of TRIzol. RNA was then isolated from the homogenates according to the manufacturer's protocol.

\subsection{Analysis of Viral Load and Viral Gene Expression in Mouse Organs}

MAV-1 viral loads were measured in organs using quantitative real-time PCR (qPCR) as previously described (Anderson et al., 2009; Nguyen et al., 2008). We use qPCR measurements of MAV-1 viral loads and viral gene expression as sensitive and rapid ways to assess viral replication in the lungs of infected mice. Peak levels of DNA viral loads and viral gene expression occur at time points at which we have been able to detect infectious virus in the lungs by plaque assay, and logarithmic decreases in DNA viral loads at later time points correlate with the clearance of infectious virus from the lungs (Weinberg et al., 2005 and unpublished data). Primers and probe (Table 1) were used to detect a 59-bp region of the MAV-1 EIA gene. $5 \mu \mathrm{l}$ of extracted DNA were added to reactions containing TaqMan Universal PCR Mix (Applied Biosystems, Foster City, CA), forward and reverse primers (each at $200 \mathrm{nM}$ final concentration) and probe ( $200 \mathrm{nM}$ final concentration) in a $25 \mu \mathrm{l}$ reaction volume. Analysis on an ABI Prism 7300 machine (Applied Biosystems, Foster City, CA) consisted of 40 cycles of 15 seconds at $90^{\circ} \mathrm{C}$ and 60 seconds at $60^{\circ} \mathrm{C}$. Standard 
curves generated using known amounts of plasmid containing the MAV-1 E1A gene were used to convert cycle threshold values for experimental samples to copy numbers of E1A DNA. Results were standardized to the ng amount of input DNA. Each sample was assayed in triplicate.

Expression of the MAV-1 hexon gene was measured using reverse transcriptase qPCR (RTqPCR). $2.5 \mu \mathrm{g}$ of RNA were reverse transcribed using MMLV reverse transcriptase (Invitrogen, Carlsbad, CA) in $20 \mu \mathrm{l}$ reactions according to the manufacturer's instructions. Primers and probe (Table 1) were used to detect a 167-bp region of the MAV-1 hexon gene. $2 \mu \mathrm{l}$ of cDNA were added to a reaction containing TaqMan Universal PCR Mix (Applied Biosystems, Foster City, CA), forward and reverse primers (each at $200 \mathrm{nM}$ final concentration) and probe ( $200 \mathrm{nM}$ final concentration) in a $25 \mu 1$ reaction volume. Separate reactions were prepared with $2 \mu \mathrm{l}$ of cDNA, $1.25 \mu \mathrm{l}$ of $20 \times$ mouse GAPDH gene expression assay (Applied Biosystems, Foster City, CA) and TaqMan Universal PCR Mix in a $25 \mu \mathrm{l}$ reaction volume. In each case, RT-qPCR analysis consisted of 40 cycles of 15 seconds at $90^{\circ} \mathrm{C}$ and 60 seconds at $60^{\circ} \mathrm{C}$. Standard curves generated using known amounts of plasmid containing the MAV-1 hexon gene or the mouse GAPDH gene were used to convert cycle threshold values for experimental samples to copy numbers of hexon and GAPDH transcripts, respectively. Copy numbers of viral transcripts were normalized to copy numbers of GAPDH transcripts for each sample. In a subset of samples prepared without using reverse transcriptase, we verified that trace amounts of contaminating DNA in the RNA samples contributed only a negligible amount to hexon copy numbers detected using RT-qPCR.

\subsection{Analysis of Cytokine and Mucus Gene Expression}

Cytokine and mucus gene expression was quantified using RT-qPCR. cDNA prepared as described above was amplified using gene expression assays for mouse CXCL1, CCL5, CCL2, and GAPDH (Applied Biosystems, Foster City, CA). $2 \mu \mathrm{l}$ of cDNA were added to reactions containing TaqMan Universal PCR Mix and $1.25 \mu \mathrm{l}$ each of $20 \times$ gene expression assays for the target cytokine and GAPDH. Primers used to detect TNF- $\alpha$, interferon (IFN)$\gamma$, Muc1, and Muc5ac are described in Table 1. For these measurements, $2 \mu 1$ of cDNA were added to reactions containing TaqMan Power SYBR Green PCR Mix (Applied Biosystems, Foster City, CA) and forward and reverse primers (each at $200 \mathrm{nM}$ final concentration) in a $25 \mu \mathrm{l}$ reaction volume. Separate reactions were prepared with primers for mouse GAPDH (Table 1, used at $167 \mathrm{nM}$ each). RT-qPCR analysis consisted of 40 cycles of 15 seconds at $90^{\circ} \mathrm{C}$ and 60 seconds at $60^{\circ} \mathrm{C}$. Quantification of target gene expression was normalized to GAPDH and expressed as fold change from control groups using the comparative $\mathrm{C}_{\mathrm{T}}$ method (Fink et al., 1998).

\subsection{Protein Extraction from Lung Homogenate}

Lung tissue was homogenized using sterile glass beads in a mini Beadbeater (Biospec Products, Bartlesville, OK) for 3 cycles of 30 seconds each. Tissue was homogenized at 100 mg per $1 \mathrm{ml}$ of CellLytic ${ }^{\mathrm{TM}}$ MT Cell Lysis Reagent (Sigma, St. Louis, MO) with protease inhibitor (complete, Mini, EDTA-free tablets; Roche Applied Science, Indianapolis, IN). Samples were centrifuged in a refrigerated microcentrifuge at $13,500 \mathrm{rpm}(17,136 \times \mathrm{g})$ for $10 \mathrm{~min}$ at $4{ }^{\circ} \mathrm{C}$ to pellet debris, and the remaining supernatant was stored at $-20^{\circ} \mathrm{C}$.

\subsection{Analysis of Cytokine Protein Production}

Measurements of cytokine protein concentrations in lung homogenate were performed by ELISA (Duoset Kits, R\&D Systems, Minneapolis, MN) according to the manufacturer's suggested protocol. 


\subsection{Detection of Muc1 Protein}

$25 \mu \mathrm{g}$ of lung homogenate protein per sample were separated on a 4-15\% gradient acrylamide gel and transferred to PVDF membrane (Bio-Rad Laboratories, Hercules, CA). Membranes were blocked overnight with tris-buffered saline-Tween (TBST; $150 \mathrm{mM} \mathrm{NaCl}$, $10 \mathrm{mM}$ Tris, $0.1 \%$ Tween 20 ) containing $5 \%$ nonfat dry milk. The membrane was then incubated overnight with a rabbit monoclonal anti-MUC1 antibody that cross-reacts with mouse Muc1 (Clone EP1024Y, OriGene, Rockville, MD; 1:2000 in 5\% nonfat dry milk/ TBST) or for $1 \mathrm{~h}$ with a rabbit polyclonal anti- $\beta$-actin antibody (sc-1616-R, Santa Cruz Biotechnology, Santa Cruz, CA; 1:500 in 5\% nonfat dry milk/TBST. Membranes were incubated for $1 \mathrm{~h}$ with secondary antibody (horseradish peroxidase-conjugated goat antirabbit IgG antibody, Pierce Biotechnology, Rockford, IL; 1:20,000 in 5\% nonfat dry milk/ TBST). Protein bands were detected with a Chemi Doc XRS (Bio-Rad Laboratories, Hercules, CA) and band densities were quantified using Quantity One software (Bio-Rad Laboratories, Hercules, CA).

\subsection{Histology Evaluation}

Lungs were fixed in 10\% formalin and embedded in paraffin, and then $5 \mu \mathrm{m}$ sections were cut for histopathology. Sections were stained with hematoxylin and eosin to evaluate cellular infiltrates. PAS staining was performed to evaluate mucus production. Digital images were obtained with an EC3 digital imaging system (Leica Microsystems) using Leica Acquisition Suite software (Leica Microsystems, Inc., Bannockburn, IL). Final images were assembled using Adobe Illustrator (Adobe Systems, San Jose, CA).

To quantify cellular inflammation in the lungs, slides were examined in a blinded fashion to determine a pathology index as previously described (Anderson et al., 2009), generating scores for the severity of cellular infiltrates around airway lumens and pneumonitis (Table 2). Each score was multiplied by a number reflecting the extent of involvement in the lung ( $5 \%$ to $25 \%=1,>25 \%$ to $50 \%=2,>50 \%=3$ ). The final pathology index was obtained by adding together the values for cellular infiltrates around airway lumens and for pneumonitis.

\subsection{Statistics}

Analysis of data for statistical significance was conducted using Prism 3 for Macintosh (GraphPad Software, Inc., La Jolla, CA). For viral load and viral gene expression data, differences between groups at a given time point were analyzed using the Mann-Whitney rank sum test. For pathology scores, cytokine and mucus gene expression data, and cytokine protein data, differences were analyzed using two-way ANOVA followed by Bonferroni's multiple comparison tests to analyze differences between two groups at each time point. $P$ values less than 0.05 were considered statistically significant.

\section{Results}

\subsection{Effects of Acute MAV-1 Infection on Lung TNF- $\alpha$ Expression}

TNF- $\alpha$ induces the expression of MUC1 in lung epithelial cells (Koga et al., 2007), and TNF- $\alpha$ inhibition suppresses MUC1 induction following in vitro RSV infection of respiratory epithelial cells (Li et al., 2010). Because of these links between TNF- $\alpha$ and Muc1, we sought to determine whether acute MAV-1 respiratory infection increased the production of TNF- $\alpha$ in the lungs. As shown in Fig. 1A, we examined time points corresponding to an early time at which viral DNA is detected in the lungs of infected mice (4 d.p.i.), a time coinciding with peak lung viral loads (7 d.p.i.), and a later time corresponding to clearance of the majority of viral DNA (14 d.p.i.). TNF- $\alpha$ mRNA levels measured by RT-qPCR were slightly increased in the lungs of infected mice compared to mock infected mice at 4 d.p.i. (Fig. 1B). This difference increased and reached statistical 
significance by 7 d.p.i. Lung TNF- $\alpha$ mRNA levels in infected animals decreased to preinfection levels by 14 d.p.i. We also used ELISA to measure TNF- $\alpha$ protein in lung homogenates at select time points (Fig. 1C). While TNF- $\alpha$ protein concentrations did not differ between mock infected and infected animals at 7 d.p.i., we detected a statistically significant increase in TNF- $\alpha$ protein in the lungs of infected mice compared to mock infected mice at 14 d.p.i.

\subsection{Effects of Acute MAV-1 Infection on Lung Muc1 Expression}

To assess the effects of MAV-1 respiratory infection on lung Muc1 production, we used RTqPCR to quantify Muc1 expression in the lungs of infected and mock infected mice. Compared to pre-infection baseline levels, no increases in Muc1 mRNA were detected in either mock infected or infected mice at 4 or 7 d.p.i. (Fig. 2A). At 14 d.p.i., the amount of Muc1 mRNA was significantly greater in the lungs of infected mice compared to mock infected mice. However, the amount of Muc1 protein in whole lung homogenate was not substantially different between mock infected and infected mice at 14 d.p.i. (Figs. 2C, 2D). mRNA levels of Muc5ac (Fig. 2B) and gob-5 (data not shown), genes encoding other mucins, were not substantially upregulated at any time point in mock infected or infected mice. Likewise, PAS staining revealed no histological evidence of significant mucus production in the lungs of infected or mock infected mice (Fig. 2E). Thus, despite the induction of TNF- $\alpha$ production in the lungs, acute MAV-1 respiratory infection was not associated with substantially increased production of Muc1 protein specifically or lung mucus production in general.

\subsection{MAV-1 Respiratory Infection in Muc1-/- Mice}

Although MAV-1 infection did not increase Muc1 production in the lungs, it remained possible that Muc1 plays a protective role, serving as a physical barrier that limits contact between MAV-1 and a target cell. We hypothesized that Muc1 deficiency would therefore facilitate interactions between virus and cell and lead to increased viral loads. To address this hypothesis, we used qPCR to quantify viral loads in the lungs of $\mathrm{Muc}^{+/+}$and $\mathrm{Muc}^{-/-}$ mice. As previously reported (Anderson et al., 2009; Nguyen et al., 2008; Weinberg et al., 2007; Weinberg et al., 2005), we used qPCR measurements of MAV-1 DNA as a sensitive way to quantify viral loads in the lungs of infected mice. As in the experiment described above, the greatest lung viral loads in $\mathrm{Muc}^{+/+}$mice were detected at 4 and 7 d.p.i. (Fig. $3 \mathrm{~A}$ ). Lung viral loads were significantly greater in $\mathrm{Muc1}^{-/-}$mice than in $\mathrm{Muc1}^{+/+}$mice at 4, 7, and 9 d.p.i., with the largest difference between groups at 9 d.p.i. No differences in lung viral loads were detected at 14 d.p.i. To provide a separate measure of viral replication, we used RT-qPCR to quantify the expression of the MAV-1 hexon gene in the lungs at 7 d.p.i. Hexon expression was significantly greater in the lungs of $\mathrm{Muc}^{-/-}$mice compared to $\mathrm{Muc1}^{+/+}$mice (Fig. 3B), further suggesting that MAV-1 replication was greater in the absence of Muc1 and that the differences in DNA viral loads were not entirely explained by differences in clearance of viral DNA from the lungs. In addition, no differences in spleen viral loads were detected between $\mathrm{Muc1}^{+/+}$and $\mathrm{Muc1}^{-/-}$mice at any time point (data not shown).

\subsection{MAV-1-Induced Pulmonary Inflammation in Muc1-/- Mice}

We anticipated that higher lung viral loads in $\mathrm{Muc1}^{-/-}$mice would be associated with a greater degree of pulmonary inflammation than in $\mathrm{Muc}^{+/+}$mice. Muc1 negatively regulates TLR-mediated inflammation (Ueno et al., 2008); the absence of such negative regulation could also lead to increased inflammation in Muc1 ${ }^{-1-}$ mice following MAV-1 infection. To determine whether this was the case, we first evaluated histologic evidence of MAV-1induced inflammation in the lungs of $\mathrm{Muc}^{+/+}$and $\mathrm{Muc1}^{-/-}$mice at multiple time points (Fig. 4). Similar to our previous reports (Weinberg et al., 2007; Weinberg et al., 2005), 
patchy areas of cellular inflammation developed in the lungs of $\mathrm{Muc}^{+/+}$mice beginning at 7 d.p.i. but were diminished by 14 d.p.i. Areas of cellular infiltration were occasionally more pronounced in the lungs of $\mathrm{Mucl}^{-/-}$mice than in $\mathrm{Muc}^{+/+}$mice at 7 d.p.i. and 14 d.p.i. (compare Figs. 4A and 4B), but these differences were subtle. Pathology index scores (Table 2) were used to quantify lung inflammation in available lung sections (Fig. 4G). There were no statistically significant differences between pathology scores in $\mathrm{Muc}^{+/+}$and $\mathrm{Muc1}^{-/-}$ mice. Pathology scores were slightly higher in $\mathrm{Muc}^{-/-}$mice compared to $\mathrm{Muc}^{+/+}$mice at 14 d.p.i., but these differences were not statistically significant.

MAV-1 infection induces the expression of multiple cytokines and chemokines in the lungs (Weinberg et al., 2007; Weinberg et al., 2005). Using RT-qPCR and ELISA, we quantified lung expression of representative chemokines in order to determine whether their induction was different in the absence of Muc1. In Muc $1^{+/+}$mice, MAV-1-induced lung expression of CXCL1, CCL5, and CCL2 peaked between 7 and 9 d.p.i. and then decreased by 14 d.p.i. (Fig. 5). CCL5 mRNA levels were lower in the lungs of $\mathrm{Muc}^{-/-}$mice than in $\mathrm{Muc}^{+/+}$ mice at 7 d.p.i. (Fig. 5C), but CCL5 protein levels were comparable between groups at this time point (Fig. 5D). Otherwise, there were no statistically significant differences in lung expression of the measured chemokines between $\mathrm{Muc}^{+/+}$and $\mathrm{Muc1}^{-/-}$mice at any time point. Likewise, there were no differences between $\mathrm{Muc}^{+/+}$and $\mathrm{Muc}^{-/-}$mice in lung expression of the cytokines IFN- $\gamma$ and TNF- $\alpha$ (data not shown).

\section{Discussion}

The mucus layer in the airways provides protection against airborne pathogens and other airborne particles (Hattrup and Gendler, 2008; Knowles and Boucher, 2002; Thornton et al., 2008). At the same time, increased mucus production during respiratory viral infection can be deleterious to the host, contributing to the pathophysiology of respiratory infection and virus-induced exacerbations of chronic lung disease (Footitt and Johnston, 2009). Many respiratory viruses have been shown to induce lung mucus production in animal models (Bartlett et al., 2008; Hamelin et al., 2006; Moore et al., 2009), but very little is known about the ability of an adenovirus to induce mucus production in the lung. Using MAV-1 in its natural host, we demonstrated that acute respiratory infection with an adenovirus did not substantially induce lung production of mucus and specifically of Muc1.

Other reports have demonstrated RSV-induced MUC1 upregulation in A549 cells (a human lung epithelial cell line) and RSV-induced Muc1 upregulation in primary mouse tracheal surface epithelial cells (Li et al., 2010). We may have missed similar effects of MAV-1 on Muc1 production in specific cell types by examining whole lung Muc1 mRNA and protein following in vivo infection. Although unlikely to explain large differences between effects of MAV-1 on Muc1 mRNA and protein, it is possible that post-translational effects on Muc1 expression, such as the release of Muc1 from the surface of epithelial cells by the action of cell surface proteases (reviewed in Brayman et al., 2004), could account for some of the differences we observed between Muc1 mRNA and protein levels. Viral infection likely affects Muc1/MUC1 expression indirectly via the actions of cytokines produced by infected cells. For instance, TNF- $\alpha$ induces MUC1 expression in A549 cells and Muc1 expression in primary mouse tracheal surface epithelial cells (Koga et al., 2007), and RSV induction of MUC1 production in a human respiratory epithelial cell line is suppressed by TNF- $\alpha$ inhibition (Li et al., 2010). Other cytokines are also capable of inducing Muc1/MUC1 production. Exposure to IFN- $\gamma$, either by itself or in combination with other cytokines such as IL- $1 \beta$ or TNF- $\beta$, increases MUC1 mRNA and protein in a variety of cell lines, including ovarian carcinoma cells lines (Clark et al., 1994), an oral epithelial cell line (Li et al., 2003), and several non-small cell lung carcinoma cell lines including A549 cells (Reddy et al., 2003). While increased IFN- $\gamma$ levels are present in the lungs of MAV-1-infected mice (Fig.

Virus Res. Author manuscript; available in PMC 2012 September 1. 
5D and Weinberg and Procario, unpublished data), it is possible that differential induction of other cytokines not measured in our study could account for the different abilities of MAV-1 and RSV to induce Muc1/MUC1 production.

To address the question of whether Muc 1 serves a protective function during adenovirus respiratory infection, we compared the susceptibilities of $\mathrm{Muc1}^{+/+}$and $\mathrm{Muc1}^{-/-}$mice using lung viral loads as a surrogate marker for susceptibility. Muc1 deficiency was associated with an approximately 1-log increase in MAV-1 viral loads in the lungs of $\mathrm{Muc1}^{-/-}$mice compared to $\mathrm{Muc}^{+/+}$mice at several time points. Changes of a similar magnitude have been described in models using HAdV-based vector gene transfer, with a 2- to 5-fold increased efficiency of gene transfer following neuraminidase treatment (removing sialic acid residues from MUC1 and other membrane glycoproteins) of primary human bronchial epithelial cells in vitro and of human airway xenografts in vivo (Arcasoy et al., 1997). Likewise, the efficiency of HAdV vector-based gene transfer is increased in Muc1-deficient mice, with $4.9 \%$ of tracheal surface area in Muc1 $1^{-/-}$mice showing evidence of gene transfer compared to $1.6 \%$ in $\mathrm{Muc}^{+/+}$mice (Stonebraker et al., 2004). One likely explanation for the differences observed in these studies as well as ours is that Muc1/MUC1 normally contributes to a physical barrier in the lung, preventing virus particles from gaining access to receptors on target cells in the airways. Muc1 is only one of many components of airway mucus (Hattrup and Gendler, 2008; Thornton et al., 2008). It seems likely that components other than Muc1 would still be able to form an effective barrier in $\mathrm{Muc}^{-1-}$ mice to impede the access of pathogens such as MAV-1 to target cells in the lungs, preventing even larger differences in lung viral loads than those that we observed in this study.

Muc1/MUC1 has anti-inflammatory properties in addition to its potential role as a physical barrier. Signaling by multiple TLRs is suppressed by MUC1 (Kim and Lillehoj, 2008; Lu et al., 2006; Ueno et al., 2008). Exaggerated pulmonary inflammation in $\mathrm{Muc}^{-1-}$ mice infected with Pseudomonas aeruginosa is associated with more efficient bacterial clearance from the lungs (Lu et al., 2006). A similar effect may occur during viral infections. For instance, RSV-induced TNF- $\alpha$ release is enhanced in $\mathrm{Muc}^{-1-}$ primary mouse tracheal epithelial cells and by MUC1 knockdown in A549 cells, whereas MUC1 overexpression suppresses TNF- $\alpha$ release induced by RSV infection of A549 cells (Li et al., 2010). We observed no pronounced differences between $\mathrm{Muc}^{+/+}$and $\mathrm{Muc1}^{-/-}$mice in MAV-1induced cellular inflammation in the lungs (Fig. 4) and lung chemokine responses (Fig. 5). Interactions between MAV-1 and specific TLRs or other pattern recognition receptors have not yet been reported. It is possible that MAV-1 induces inflammatory responses via pattern recognition receptors or other mechanisms that are not modulated by Muc1 and so do not differ in the absence of Muc1. It is also possible that Muc1 deficiency led to enhanced production of inflammatory mediators not measured in our study. However, MAV-1 viral loads were equivalent in the lungs of $\mathrm{Muc}^{+/+}$and $\mathrm{Muc}^{-/-}$mice by 14 d.p.i. (Fig. 3), suggesting that any missed effect of Muc1 deficiency on MAV-1-induced inflammation did not substantially alter the kinetics of virus clearance from the lungs and therefore had little biological relevance.

In summary, we show that MAV-1 respiratory infection did not affect Muc1 expression in vivo. Viral loads were greater in Muc $1^{-/-}$mice than in $\mathrm{Muc}^{+/+}$mice, suggesting that Muc1 contributes to a physical barrier that inhibits MAV-1 access to target cells in the airways. The absence of substantial changes in virus-induced lung inflammation in $\mathrm{Muc1}^{-/-}$mice compared to $\mathrm{Muc}^{+/+}$controls suggests that the anti-inflammatory functions of Muc1 do not play a prominent role in MAV-1 respiratory infection. Overall, Muc1 is likely to be protective in the context of acute MAV-1 respiratory infection. However, as with HAdVbased vectors for gene delivery (Arcasoy et al., 1997; Stonebraker et al., 2004), Muc1 (and 
MUC1 in humans) may impede efforts to use MAV-1 or other non-human adenoviruses as alternative platforms for gene delivery.

\section{Acknowledgments}

We thank Kathy Spindler for obtaining the Muc1 ${ }^{-/-}$mice and suggesting their use in our research. We thank Michael Imperiale for helpful review of the manuscript. We appreciate the assistance of Joel Whitfield with ELISA measurements, which were performed by the University of Michigan Cancer Center Core. Histology was performed by the University of Michigan Research Histology and IHC Laboratory, which is supported in part by the National Institutes of Health through the University of Michigan's Cancer Center Support Grant (P30 CA46592). This research was supported by an NIH K08 HL083103 award and a Janette Ferrantino Pediatric Investigator Award to Jason Weinberg. The funders had no role in study design, data collection and analysis, decision to publish, or preparation of the manuscript. No additional external funding was received for this study.

\section{References}

Anderson VE, Nguyen Y, Weinberg JB. Effects of allergic airway disease on mouse adenovirus type 1 respiratory infection. Virology. 2009; 391(1):25-32. [PubMed: 19564030]

Arcasoy SM, Latoche J, Gondor M, Watkins SC, Henderson RA, Hughey R, Finn OJ, Pilewski JM. MUC1 and other sialoglycoconjugates inhibit adenovirus-mediated gene transfer to epithelial cells. Am J Respir Cell Mol Biol. 1997; 17(4):422-435. [PubMed: 9376117]

Bartlett NW, Walton RP, Edwards MR, Aniscenko J, Caramori G, Zhu J, Glanville N, Choy KJ, Jourdan P, Burnet J, Tuthill TJ, Pedrick MS, Hurle MJ, Plumpton C, Sharp NA, Bussell JN, Swallow DM, Schwarze J, Guy B, Almond JW, Jeffery PK, Lloyd CM, Papi A, Killington RA, Rowlands DJ, Blair ED, Clarke NJ, Johnston SL. Mouse models of rhinovirus-induced disease and exacerbation of allergic airway inflammation. Nat Med. 2008; 14(2):199-204. [PubMed: 18246079]

Brayman M, Thathiah A, Carson DD. MUC1: a multifunctional cell surface component of reproductive tissue epithelia. Reprod Biol Endocrinol. 2004; 2:4. [PubMed: 14711375]

Cauthen AN, Welton AR, Spindler KR. Construction of mouse adenovirus type 1 mutants. Methods Mol Med. 2007; 130:41-59. [PubMed: 17401163]

Chang JF, Zhao HL, Phillips J, Greenburg G. The epithelial mucin, MUC1, is expressed on resting T lymphocytes and can function as a negative regulator of T cell activation. Cell Immunol. 2000; 201(2):83-88. [PubMed: 10831317]

Clark S, McGuckin MA, Hurst T, Ward BG. Effect of interferon-gamma and TNF-alpha on MUC1 mucin expression in ovarian carcinoma cell lines. Dis Markers. 1994; 12(1):43-50. [PubMed: 7842630]

Fink L, Seeger W, Ermert L, Hanze J, Stahl U, Grimminger F, Kummer W, Bohle RM. Real-time quantitative RT-PCR after laser-assisted cell picking. Nat Med. 1998; 4(11):1329-1333. [PubMed: 9809560]

Footitt J, Johnston SL. Cough and viruses in airways disease: mechanisms. Pulm Pharmacol Ther. 2009; 22(2):108-113. [PubMed: 19480062]

Gendler SJ. MUC1, the renaissance molecule. J Mammary Gland Biol Neoplasia. 2001; 6(3):339-353. [PubMed: 11547902]

Ginsberg HS, Moldawer LL, Sehgal PB, Redington M, Kilian PL, Chanock RM, Prince GA. A mouse model for investigating the molecular pathogenesis of adenovirus pneumonia. Proc. Natl. Acad. Sci. USA. 1991; 88(5):1651-1655. [PubMed: 1848005]

Hamelin ME, Prince GA, Gomez AM, Kinkead R, Boivin G. Human metapneumovirus infection induces long-term pulmonary inflammation associated with airway obstruction and hyperresponsiveness in mice. J Infect Dis. 2006; 193(12):1634-1642. [PubMed: 16703506]

Hattrup CL, Gendler SJ. Structure and function of the cell surface (tethered) mucins. Annu Rev Physiol. 2008; 70:431-457. [PubMed: 17850209]

Horwitz, MS. Adenoviruses. In: Knipe, DM.; Howley, P.M. (Eds.), editors. Fields Virology. Vol. Vol. 2. Lippincott Williams \& Wilkins; Philadelphia: 2001. p. 2301-2327.2 vols 
Kajon AE, Gigliotti AP, Harrod KS. Acute inflammatory response and remodeling of airway epithelium after subspecies B1 human adenovirus infection of the mouse lower respiratory tract. J. Med. Virol. 2003; 71(2):233-244. [PubMed: 12938198]

Kim KC, Lillehoj EP. MUC1 mucin: a peacemaker in the lung. Am J Respir Cell Mol Biol. 2008; 39(6):644-647. [PubMed: 18617677]

Knowles MR, Boucher RC. Mucus clearance as a primary innate defense mechanism for mammalian airways. J Clin Invest. 2002; 109(5):571-577. [PubMed: 11877463]

Koga T, Kuwahara I, Lillehoj EP, Lu W, Miyata T, Isohama Y, Kim KC. TNF-alpha induces MUC1 gene transcription in lung epithelial cells: its signaling pathway and biological implication. Am J Physiol Lung Cell Mol Physiol. 2007; 293(3):L693-701. [PubMed: 17575006]

Kojaoghlanian T, Flomenberg P, Horwitz MS. The impact of adenovirus infection on the immunocompromised host. Rev. Med. Virol. 2003; 13(3):155-171. [PubMed: 12740831]

Li X, Wang L, Nunes DP, Troxler RF, Offner GD. Pro-inflammatory cytokines up-regulate MUC1 gene expression in oral epithelial cells. J Dent Res. 2003; 82(11):883-887. [PubMed: 14578499]

Li Y, Dinwiddie DL, Harrod KS, Jiang Y, Kim KC. Anti-inflammatory effect of MUC1 during respiratory syncytial virus infection of lung epithelial cells in vitro. Am J Physiol Lung Cell Mol Physiol. 2010; 298:L558-L563. [PubMed: 20081068]

Lillehoj EP, Hyun SW, Kim BT, Zhang XG, Lee DI, Rowland S, Kim KC. Muc1 mucins on the cell surface are adhesion sites for Pseudomonas aeruginosa. Am J Physiol Lung Cell Mol Physiol. 2001; 280(1):L181-187. [PubMed: 11133508]

Lu W, Hisatsune A, Koga T, Kato K, Kuwahara I, Lillehoj EP, Chen W, Cross AS, Gendler SJ, Gewirtz AT, Kim KC. Cutting edge: enhanced pulmonary clearance of Pseudomonas aeruginosa by Muc1 knockout mice. J Immunol. 2006; 176(7):3890-3894. [PubMed: 16547220]

Moore ML, Chi MH, Luongo C, Lukacs NW, Polosukhin VV, Huckabee MM, Newcomb DC, Buchholz UJ, Crowe JE Jr. Goleniewska K, Williams JV, Collins PL, Peebles RS Jr. A chimeric A2 strain of respiratory syncytial virus (RSV) with the fusion protein of RSV strain line 19 exhibits enhanced viral load, mucus, and airway dysfunction. J Virol. 2009; 83(9):4185-4194. [PubMed: 19211758]

Nguyen Y, McGuffie BA, Anderson VE, Weinberg JB. Gammaherpesvirus modulation of mouse adenovirus type 1 pathogenesis. Virology. 2008; 380(2):182-190. [PubMed: 18768196]

Reddy PK, Gold DV, Cardillo TM, Goldenberg DM, Li H, Burton JD. Interferon-gamma upregulates MUC1 expression in haematopoietic and epithelial cancer cell lines, an effect associated with MUC1 mRNA induction. Eur J Cancer. 2003; 39(3):397-404. [PubMed: 12565994]

Spicer AP, Duhig T, Chilton BS, Gendler SJ. Analysis of mammalian MUC1 genes reveals potential functionally important domains. Mamm Genome. 1995; 6(12):885-888. [PubMed: 8747930]

Stonebraker JR, Wagner D, Lefensty RW, Burns K, Gendler SJ, Bergelson JM, Boucher RC, O'Neal WK, Pickles RJ. Glycocalyx restricts adenoviral vector access to apical receptors expressed on respiratory epithelium in vitro and in vivo: role for tethered mucins as barriers to lumenal infection. J Virol. 2004; 78(24):13755-13768. [PubMed: 15564484]

Therien AG, Bernier V, Weicker S, Tawa P, Falgueyret JP, Mathieu MC, Honsberger J, Pomerleau V, Robichaud A, Stocco R, Dufresne L, Houshyar H, Lafleur J, Ramachandran C, O'Neill GP, Slipetz D, Tan CM. Adenovirus IL-13-induced airway disease in mice: a corticosteroid-resistant model of severe asthma. Am J Respir Cell Mol Biol. 2008; 39(1):26-35. [PubMed: 18258919]

Thornton DJ, Rousseau K, McGuckin MA. Structure and function of the polymeric mucins in airways mucus. Annu Rev Physiol. 2008; 70:459-486. [PubMed: 17850213]

Ueno K, Koga T, Kato K, Golenbock DT, Gendler SJ, Kai H, Kim KC. MUC1 mucin is a negative regulator of toll-like receptor signaling. Am J Respir Cell Mol Biol. 2008; 38(3):263-268. [PubMed: 18079492]

Walls T, Shankar AG, Shingadia D. Adenovirus: an increasingly important pathogen in paediatric bone marrow transplant patients. Lancet Infect. Dis. 2003; 3(2):79-86. [PubMed: 12560192]

Weinberg JB, Jensen DR, Gralinski LE, Lake AR, Stempfle GS, Spindler KR. Contributions of E1A to mouse adenovirus type 1 pathogenesis following intranasal inoculation. Virology. 2007; 357(1): 54-67. [PubMed: 16962154]

Virus Res. Author manuscript; available in PMC 2012 September 1. 
Weinberg JB, Stempfle GS, Wilkinson JE, Younger JG, Spindler KR. Acute respiratory infection with mouse adenovirus type 1. Virology. 2005; 340(2):245-254. [PubMed: 16054189] 


\section{Highlights}

- We used MAV-1 to determine the role of Muc1 in adenovirus pathogenesis.

- MAV-1 did not increase lung Muc1 production.

- MAV-1 viral loads were higher in the lungs of Muc1-deficient mice.

- Muc1 deficiency did not affect MAV-1-induced lung inflammation.

- Muc1 likely contributes to a physical barrier protecting against MAV-1 infection. 

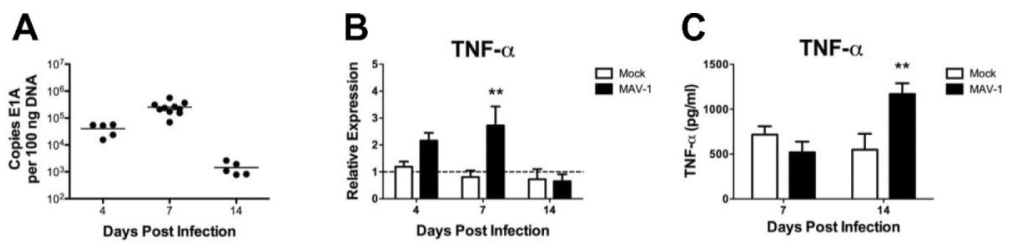

Figure 1.

In vivo induction of TNF- $\alpha$ by MAV-1. Mice were infected intranasally with MAV-1 or mock infected with conditioned media. (A) RNA was extracted from lungs harvested at the indicated time points and RT-qPCR was used to quantify the expression of TNF- $\alpha$. Data for both experimental groups are presented as expression relative to naïve control mice, whose value is set at 1 (indicated with horizontal dashed line). Combined data from two independent experiments (total $n=5-14$ mice per group) are presented as means \pm S.E.M. (B) ELISA was used to quantify TNF- $\alpha$ protein in lung homogenate obtained from a subset of mice. Combined data from 5 mice per group are presented as means \pm S.E.M. $* * P<0.01$ compared to uninfected mice using two-way ANOVA followed by Bonferroni's multiple comparison tests at a given time point. 

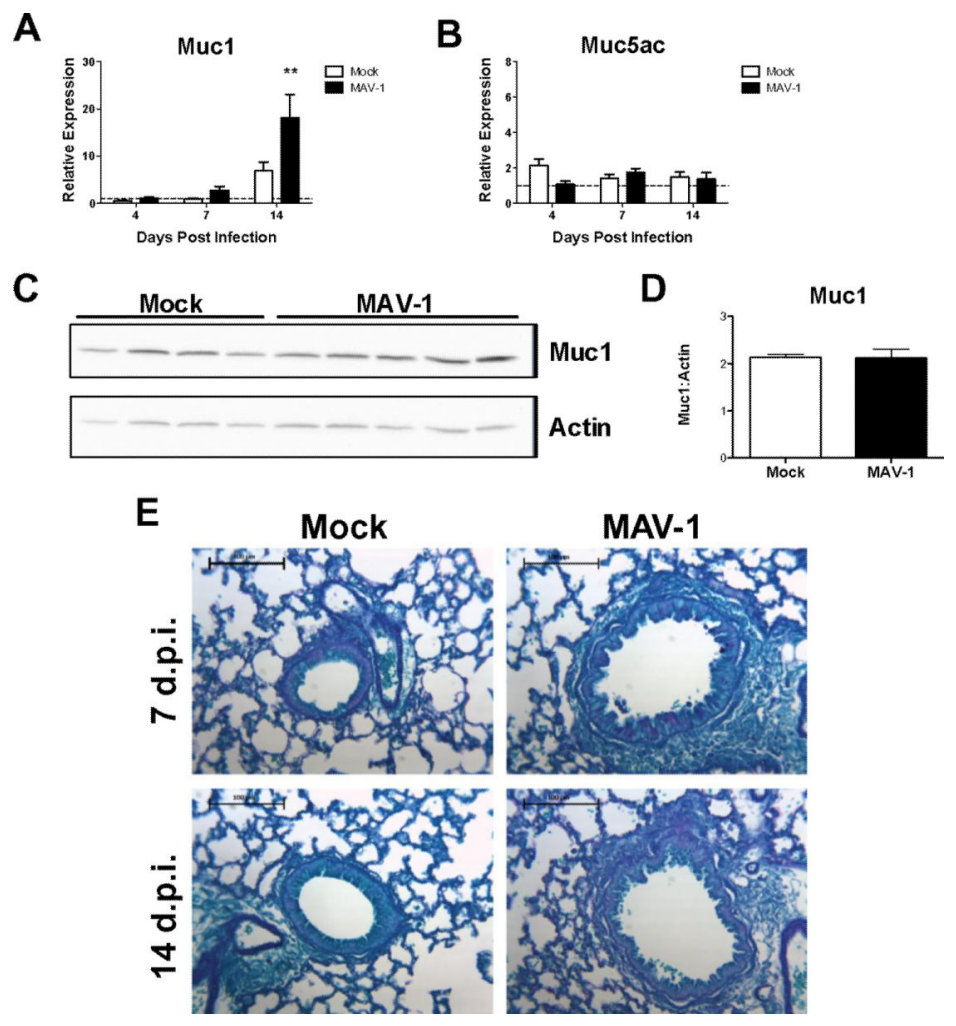

Figure 2.

In vivo induction of Muc1 by MAV-1. Mice were infected intranasally with MAV-1 or mock infected with conditioned media. RNA was extracted from lungs harvested at the indicated time points. RT-qPCR was used to quantify the expression of (A) Muc1 and (B) Muc5ac. Data for both experimental groups are presented as expression relative to naïve control mice, whose value is set at 1 (indicated with horizontal dashed line). Combined data from two independent experiments (total $\mathrm{n}=5-14$ mice per group) are presented as means \pm S.E.M. ${ }^{* *} P<0.01$ compared to uninfected mice using two-way ANOVA followed by

Bonferroni's multiple comparison tests at a given time point. (C) Western blot was used to detect Muc1 protein in whole lung homogenate obtained from representative animals at 14 d.p.i. (D) Quantified Western blot data are presented as the ratio of Muc1 to actin densities $(\mathrm{n}=4$ to 5 per group, means \pm S.E.M). (E) Lung sections were stained with PAS to evaluate mucus production in the lungs. Scale bars, $100 \mu \mathrm{m}$. 
A

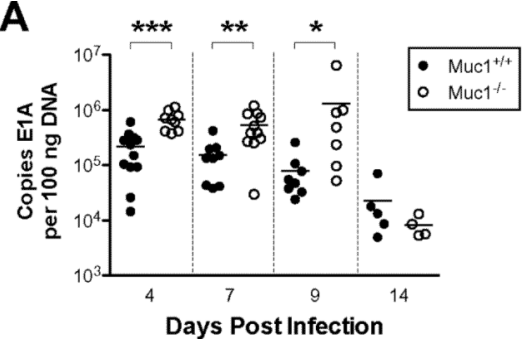

B

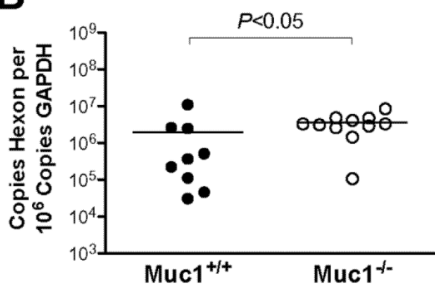

Figure 3.

Viral loads in the lungs of $\mathrm{Muc}^{-/-}$mice. Muc1 ${ }^{-/-}$mice and Muc1+/+ control mice were infected intranasally with MAV-1. (A) DNA was extracted from lungs harvested at the indicated time points. qPCR was used to quantify MAV-1 genome copies in lung DNA. DNA viral load data are expressed as copies of MAV-1 genome per $100 \mathrm{ng}$ of input DNA. (B) RNA was extracted from lungs of mice at 7 d.p.i. and RT-qPCR was used to quantify expression of the MAV-1 hexon gene. Data are expressed as copies of hexon per $10^{6}$ copies of GAPDH. Combined data from three independent experiments are presented with individual circles representing values for individual mice and horizontal bars representing means for each group. $* P<0.05$, $* * P<0.01$, and $* * * P<0.001$ comparing two groups at a given time point using Mann-Whitney rank sum test. 

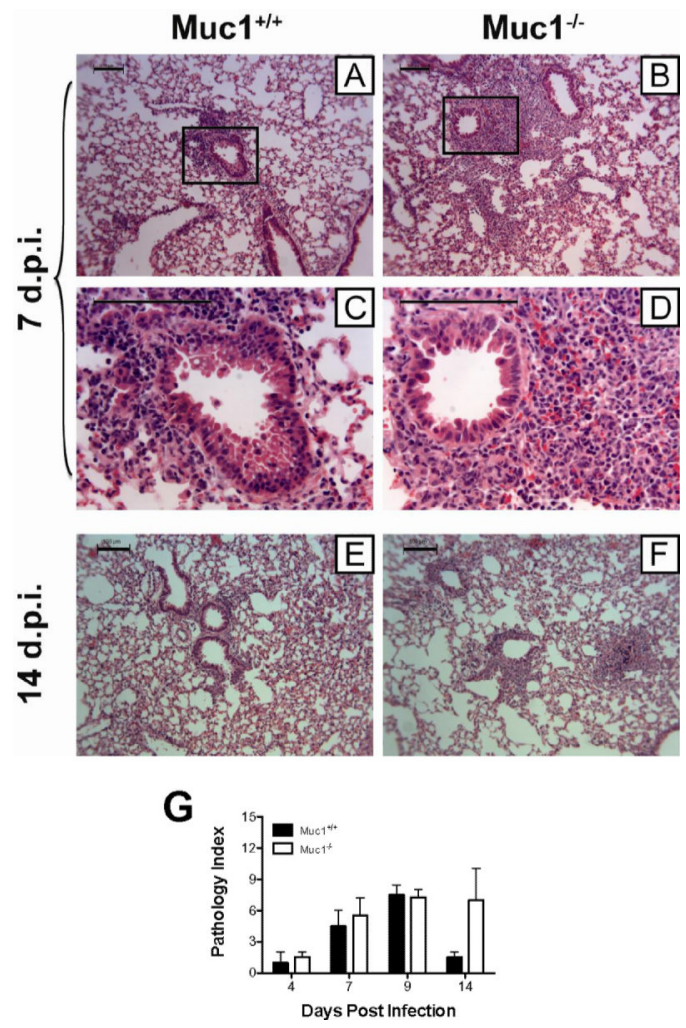

Figure 4.

MAV-1-induced lung inflammation in $\mathrm{Muc1}^{-/-}$mice. $\mathrm{Muc1}^{-/-}$mice and $\mathrm{Muc1}^{+/+}$control mice were infected intranasally with MAV-1. Lungs were harvested at 7 d.p.i. (A-D) and 14 d.p.i. (E, F). Hematoxylin and eosin-stained sections were prepared from paraffin-embedded sections. Regions delineated by the rectangles in A and B are further magnified in $\mathrm{C}$ and $\mathrm{D}$.

Scale bars, $100 \mu \mathrm{m}$. (G) Pathology index scores were generated to quantify cellular inflammation in the lungs of $\mathrm{Muc}^{+/+}$and $\mathrm{Muc1}^{-/-}$mice. Data are presented as means \pm S.E.M. at each time point ( $\mathrm{n}=2$ at 4 and 14 d.p.i., $\mathrm{n}=4$ at 7 and 9 d.p.i.). 
A

Figure 5.
CXCL1

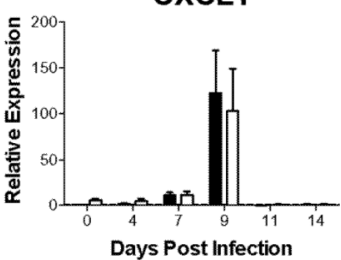

C

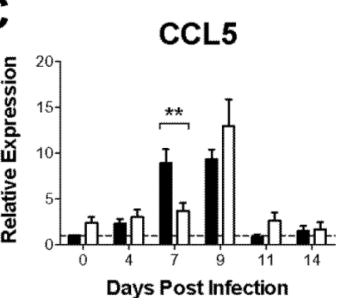

E

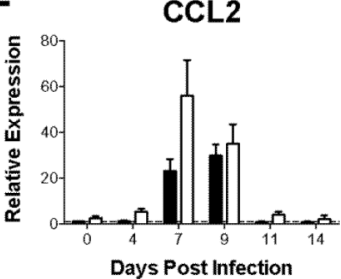

B
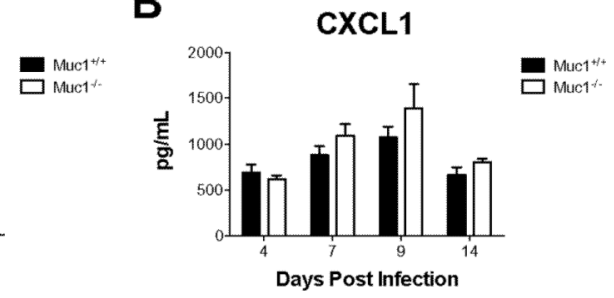

D

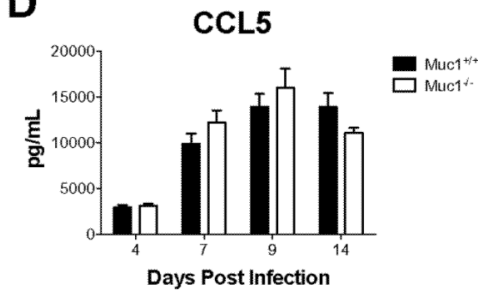

$\mathbf{F}$

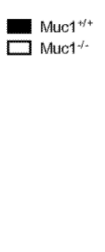

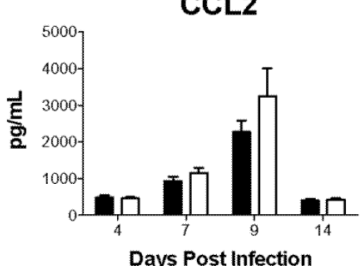

MAV-1-induced chemokine and cytokine expression in $\mathrm{Muc1}^{-/-}$mice. $\mathrm{Muc}^{-/-}$mice and $\mathrm{Muc}^{+/+}$control mice were infected intranasally with MAV-1. (A, C, E) RNA was extracted from lungs harvested at the indicated time points. RT-qPCR was used to quantify the expression of the indicated chemokines. Data for both experimental groups are presented as expression relative to uninfected control mice, whose value is set at 1 (indicated with horizontal dashed line). Data ( $\mathrm{n}=5$ to 11 mice per group) are presented as means \pm S.E.M. ** $P<0.01$ compared to Muc $1^{+/+}$controls at the same time point. (B, D, F) ELISA was used to quantify the indicated chemokines in whole lung homogenate. Data are presented as means \pm S.E.M. ( $n=4$ to 13 per group). 


\section{Table 1}

Primers and probes used for real-time PCR analysis

\begin{tabular}{lll}
\hline Target & Oligonucleotide & Sequence (5' to 3') \\
\hline MAV-1 E1A & Forward primer & GCACTCCATGGCAGGATTCT \\
& Reverse primer & GGTCGAAGCAGACGGTTCTTC \\
& Probe & TACTGCCACTTCTGC \\
\hline MAV-1 Hexon & Forward primer & GGCCAACACTACCGACACTT \\
& Reverse primer & TTTTGTCCTGTGGCATTTGA \\
& Probe & CATTCCAGCCAACTTATGGCTCGGC \\
\hline IFN- $\gamma$ & Forward primer & AAAGAGATAATCTGGCTCTGC \\
& Reverse primer & GCTCTGAGACAATGAACGCT \\
\hline TNF- $\alpha$ & Forward primer & CCACCACGCTCTTCTGTCTAC \\
& Reverse primer & AGGGTCTGGGCCATAGAACT \\
\hline Muc1 & Forward primer & CACACTCACGGACGCTACGT \\
& Reverse primer & TACCTGCCGAAACCTCCTCAT \\
\hline Muc5ac & Forward primer & CCAGCACCATCTCTACAACCC \\
\hline RAPDH & Foverse primer & GCAAAGCTCCTGTTTGCACTC \\
\hline & Reverse primer & GGAACCACCAACTGCTTAG \\
\hline
\end{tabular}

Virus Res. Author manuscript; available in PMC 2012 September 1. 
Table 2

Quantification of cellular inflammation in histologic specimens.

\begin{tabular}{l|l|l}
\hline Score $^{\boldsymbol{a}}$ & Cellular Infiltrates Around Airway Lumens & Pneumonitis \\
\hline 0 & No infiltrates & No infiltrates \\
\hline $\mathbf{I}$ & 1 to 3 cell diameters thick & Increased cells visible only at high power \\
\hline 2 & 4 to 10 cell diameters thick & Easily seen cellular infiltrates \\
\hline 3 & $>10$ cell diameters thick & Extensive consolidation by inflammatory cells \\
\hline
\end{tabular}

${ }^{a} \mathrm{~A}$ score from 0 to 3 was given for each of the two categories. The score for each category was multiplied by a number reflecting the extent of involvement in the specimen ( $5 \%$ to $25 \%=1,>25 \%$ to $50 \%=2,>50 \%=3$ ). The final pathology index score was obtained by adding together values for each category, resulting in a total score that could range from 0 to 18 . 